Journal: Construction and Building Materials - JCBM_119074 (April 2020)

\title{
The Characterization of Chloride Effect on Concrete Water Sorption and its Application in the Modelling of Concrete Conditions in Tidal Zones
}

\author{
*Yu Wang ${ }^{1}$, Hayder Oleiwi ${ }^{2}$, Chung-Yue Wang ${ }^{3}$, Nan Xiang $^{4}$, Jian Geng $^{5}$ \\ 1. School of Science, Engineering \& Environment, University of Salford, Manchester M5 4WT, \\ UK \\ 2. College of Engineering, University of Thi-Qar, Nasiriyah, Iraq \\ 3. Department of Civil Engineering, National Central University, Taiwan, R. China \\ 4. School of Civil Engineering, Chongqing Jiao Tong University, Chongqing, PR. China \\ 5. Centre of Green Building Materials and Waste Resources Reuse, Ningbo Institute of \\ Technology, Zhejiang University, PR. China
}

\section{*Corresponding Author: y.wang@salford.ac.uk}

\begin{abstract}
Concrete exposed to cyclic wetting and drying in salty water conditions is thought to be subjected to an accelerated ingress of chloride from the outside environment, and prone to a worsening deterioration process inside. Additionally, there is an osmotic effect on salty water flow in porous concrete. However, so far, a fully profound understanding of the coupled cyclic wetting-drying and osmosis effects on the chloride movement in concrete is still limited. This paper reports on a comprehensive study on the topic. A series of experimental tests was conducted initially for the vapour-water sorption isotherm (VWSI) of normal concrete of different porosity and chloride content. Thereafter, a novel mathematical model was proposed and validated to characterise the effect of chloride salt on the vapour absorption and water retention behaviour of concrete. Finally, the proposed characteristic model was implemented in a numerical model to simulate chloride ingress in concrete in tidal zones. The vapour-water sorption isotherm model successfully provides an effective tool to quantify the coupled influence of cyclic wetting-drying and osmosis on chloride transportation in concrete.
\end{abstract}

Keywords: Concrete, Chloride, Osmotic effect, Unsaturated suction, Water saturation. 
Journal: Construction and Building Materials - JCBM_119074 (April 2020)

\section{Introduction}

Chloride plays an important role in the rebar corrosion of reinforced concrete structures serving in saline environments. The time taken for chloride from the outside environment to reach the surface of reinforcement in concrete structures to a critical amount decisively influences the total life span of these structures. Predicting and making an assessment on chloride transport in concrete has been a topical research since the end of last century [1-5]. Since then it has been widely recognised that chloride ingress in concrete from external saline environments is mainly driven by pore water infiltration and chloride diffusion [6.7]. Meanwhile, there are many factors which have direct influences on these two major mechanisms, such as temperature, carbonation and the local electrochemical potential gradient $[3,8,9]$. In addition, it has been noted that structures exposed to cyclic wetting and drying conditions are subject to accelerated chloride penetration under the entangled effects of diffusion and convection mechanisms [10-12].

Computer modelling has become an effective tool adopted for the appraisal of the service condition of concrete structures exposed to saline environments. There are a large number of publications on the topic. Typically, the proposed models can be classified into two types. Type 1 uses Fick's second law, which adopts an apparent diffusion coefficient to take account of the various influences $[13,14]$. Type 2 explicitly describes the coupled pore water convection and chloride diffusion mechanisms using a water infiltration model together with Fick's law [15]. The environmental and the material factors, which link to the two transport mechanisms, can be specified in the modelling [16] (for example, the influence of cylic wetting and drying conditions [17-19], the effect of the electrical double layer at the pore surfaces [20], the osmotic effect [21], and the effect of double-porosity in concrete [22]).

The cyclic wetting-drying and the osmotic effect together have a combined effect on both the chloride diffusion and the pore water infiltration in concrete. However, so far, understanding and quantifying the two coupled mechanisms are still limited [13,23]. Considering the two mechanisms together with other factors, such as the pore structure of concrete [24-26], are reported upon even less. Thus far, more systemic studies, from experiments to mathematic characterization, are still required to evaluate these coupled mechanisms accurately aiming to provide a reliable tool for the assessment of concrete durability exposed to chloride attack. As an effort to contribute to this purpose, this paper initially reports on an experiment regarding the vapour-water absorption 
Journal: Construction and Building Materials - JCBM_119074 (April 2020)

isotherm of Portland cement concrete of different chloride content and porosity. Thereafter, a novel characteristics' model based on the fundamental physics of vapour-water absorption is proposed and validated using the experimental data. Finally, as a demonstration of a practical application, the model is implemented to simulate chloride ingress in concrete in a region exposed to tidal splash.

\section{Experiment}

\subsection{Mix Design and Concrete Specimens}

Locally produced Portland limestone cement, CEM II/A-LL conforming to the British standard BS EN 197-1: 2011, was used for the concrete mixes at $390 \mathrm{~kg} / \mathrm{m}^{3}$. Natural sand of the maximum size of $4.75 \mathrm{~mm}$ and a relative density of 2.47 was used for the fine aggregate at $580 \mathrm{~kg} / \mathrm{m}^{3}$. The coarse aggregate was limestone of $10 \mathrm{~mm}$ maximum size and 2.49 specific gravity and used at $1125 \mathrm{~kg} / \mathrm{m}^{3}$. The mix of concrete followed the British standard, BS 1881-125:2013.

Four different chloride contents were prepared by adding $\mathrm{NaCl}$ in the mix water, they were $0,1.5$, 3 and $4.5 \%$ of the cement mass, respectively. Three different water to cement ratios (w/c) of 0.4 , 0.5 and 0.6 were used for all these $\mathrm{NaCl}$ mixes. All the cast concrete samples were cured for 28 days by submerging in the water of the same chloride content as that used for their mixes. This fully saturated curing method aims for an even distribution of chloride in the concrete samples and, therefore, makes the test results more reliable. For each $\mathrm{NaCl}$ mix and w/c, three specimens were prepared for individual specific property measuring, and the final result took the average of the triplicate measurements.

\subsection{Vapour-Water Sorption Isotherm}

After 28 days, all the cured saturated samples were weighed in their surface dry states. Thereafter, they were put in environmental chambers with three controlled relative humidity $(\mathrm{RH})$ values, which were $35 \%, 60 \%$ and $80 \%$, respectively. These samples were kept in the chambers at a controlled temperature of $21^{\circ} \mathrm{C}$ for enough time until no weight change was observed (less than 0.001g). Then the equilibrium water content for each of the RH controlled conditions was measured using the weighing method on an electrical scale of an accuracy of $0.001 \mathrm{~g}$. The results presented the vapour-water sorption isotherm or the vapour absorption and water retention 
Journal: Construction and Building Materials - JCBM_119074 (April 2020)

94 characteristics of the concrete samples. Fig. 1 compares the measured equilibrium of (a) the pore water content, and (b) the calculated corresponding pore water saturation (the ratio of unsaturated pore water content to the fully saturated water content) in these concrete samples when exposed to different environmental humidities. Table 1 presents the measured porosity of the concrete samples using different w/c ratios. It can be seen that for the hardened concrete of a specific porosity, when exposed to a certain environmental humidity, the higher the chloride salt content, the higher the pore water content and the pore water saturation degree. The trend is particularly highlighted in the lower middle range of the pore water saturation of $0.2 \sim 0.5$ as shown in Fig. 1(b). This phenomena can be explained by the enhanced capillary condensation in this range under high salt content in both pore water and the solid matrix of concrete.

Table 1. Measured average concrete porosity vs w/c

\begin{tabular}{|c|c|c|c|}
\hline w/c & 0.4 & 0.5 & 0.6 \\
\hline Porosity & 0.16 & 0.19 & 0.21 \\
\hline
\end{tabular}

106

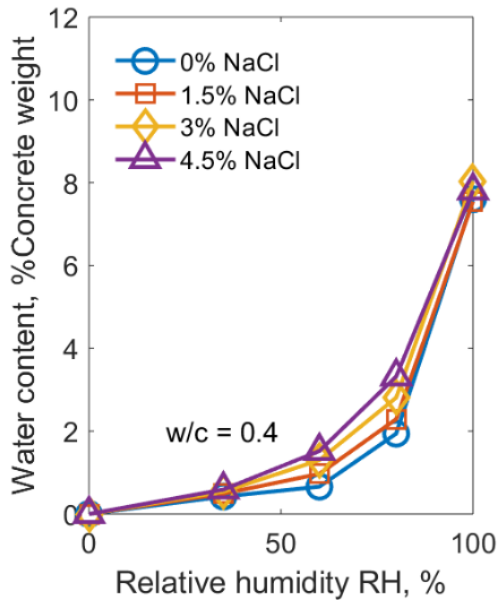

108
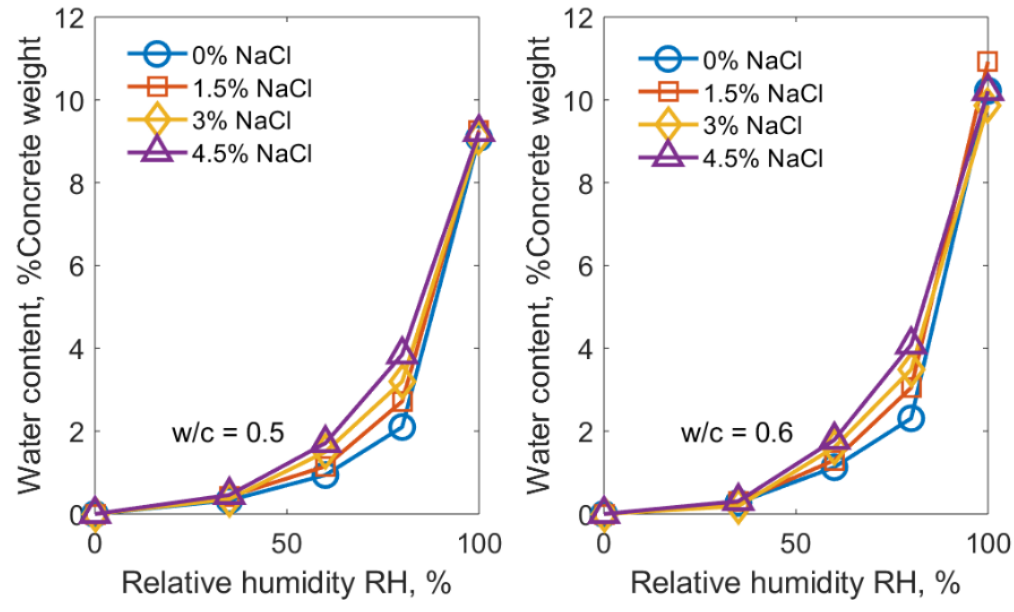

(a) Water content vs RH 

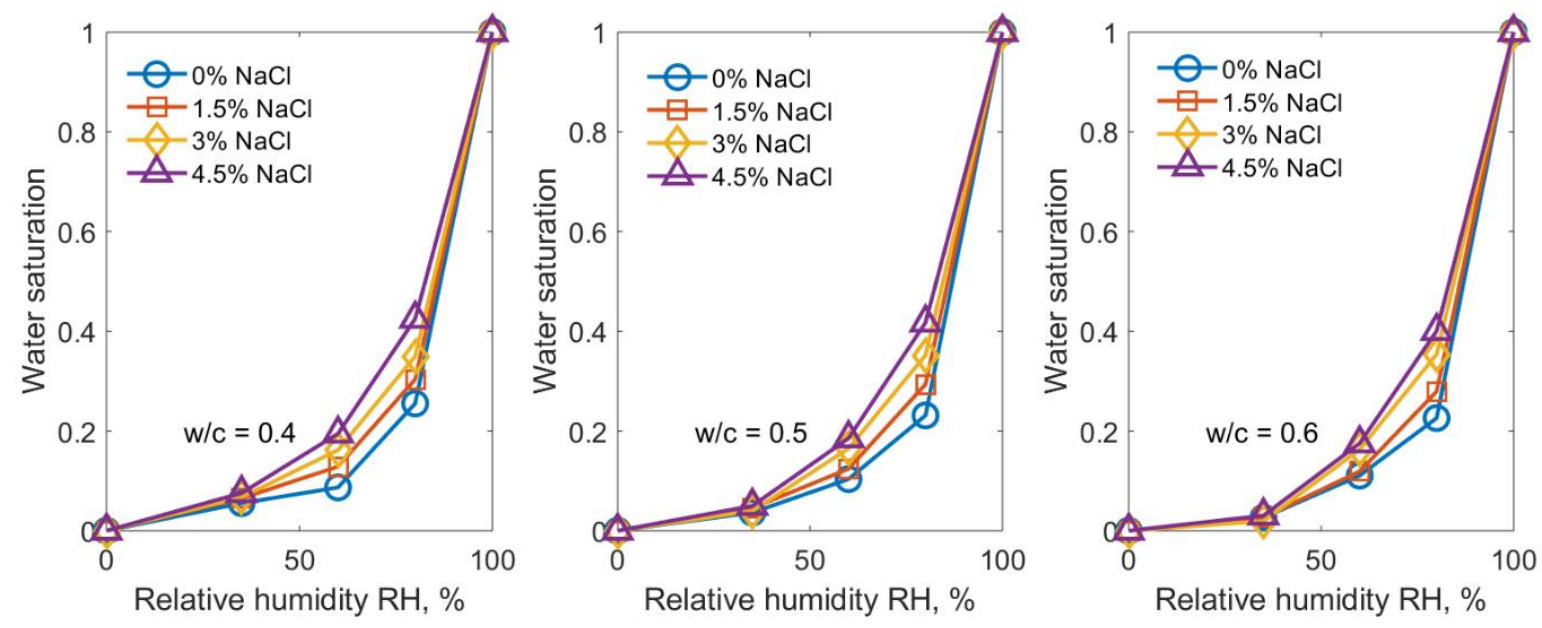

(b) Pore water saturation vs RH

Figure 1. Concrete water retention characteristics under different $\mathrm{NaCl}$ contents

113 Fig. 2 replots the data in Fig. 1 to compare the effect of porosity under the condition of the same 114 chloride salt contents. It can be seen that the influence of the porosity on the vapour absorption 115 and water retention characteristics is much less than that of the salt content. The porosity effect is 116 particularly obvious at a low water saturation degree less than 0.2 . In the range, it can be seen that, 117 under the same environmental humidity, the lower the porosity the higher the water saturation, and 118 the trend is further enhanced by a high $\mathrm{NaCl}$ content. This can be explained by the fact that the 119 lower the porosity the higher the percentage of small pores. A large number of small pores 120 increases both the total pore surface area and the water capillary condensation inside them. 

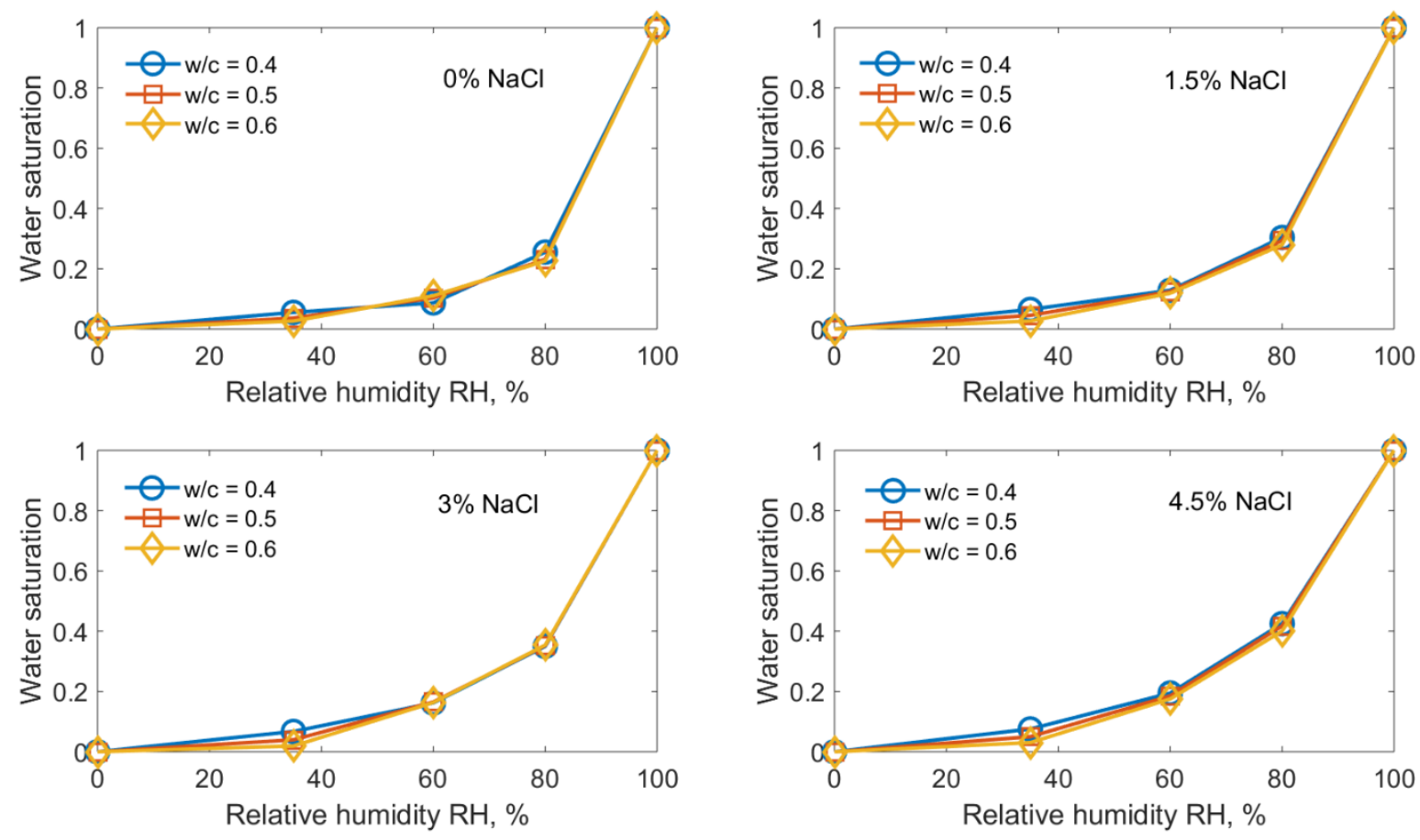

Figure 2. The effect of porosity on water retention characteristics

\subsection{Chloride Binding Isotherm}

At the end, all the samples of added $\mathrm{NaCl}$ were measured for their actual total and free chloride contents after the submerged curing, respectively. Three cylindrical cores of the size $12 \mathrm{~mm} \times 100$ $\mathrm{mm}$ (diameter $\times$ length) evenly distributed along the central line of a cubic sample $(100 \mathrm{~mm} \times 100$ $\mathrm{mm} \times 100 \mathrm{~mm}$ ) were taken from each mix sample and crushed into powder. The powder of the three cylindrical cores were mixed together to represent the sample of each mixture. The test followed the method specified in the standards [27,28]. Fig. 3 shows the measured free and total chloride contents in terms of dry concrete weights of samples (using concrete weight rather than cement weight is considered to be more convenient for in-situ practice). Four extra data in the cases of w/c $=0.4 \& 0.5$ were obtained from the other samples prepared in another study [29]. It can be seen that the measured free and total chlorides in the range of chloride contents present a reasonable linear relationship. These fitting results show that the higher the w/c the higher the slope of the fitting linear trend. It means that the bound chloride content in the concrete of higher porosity decreases. 

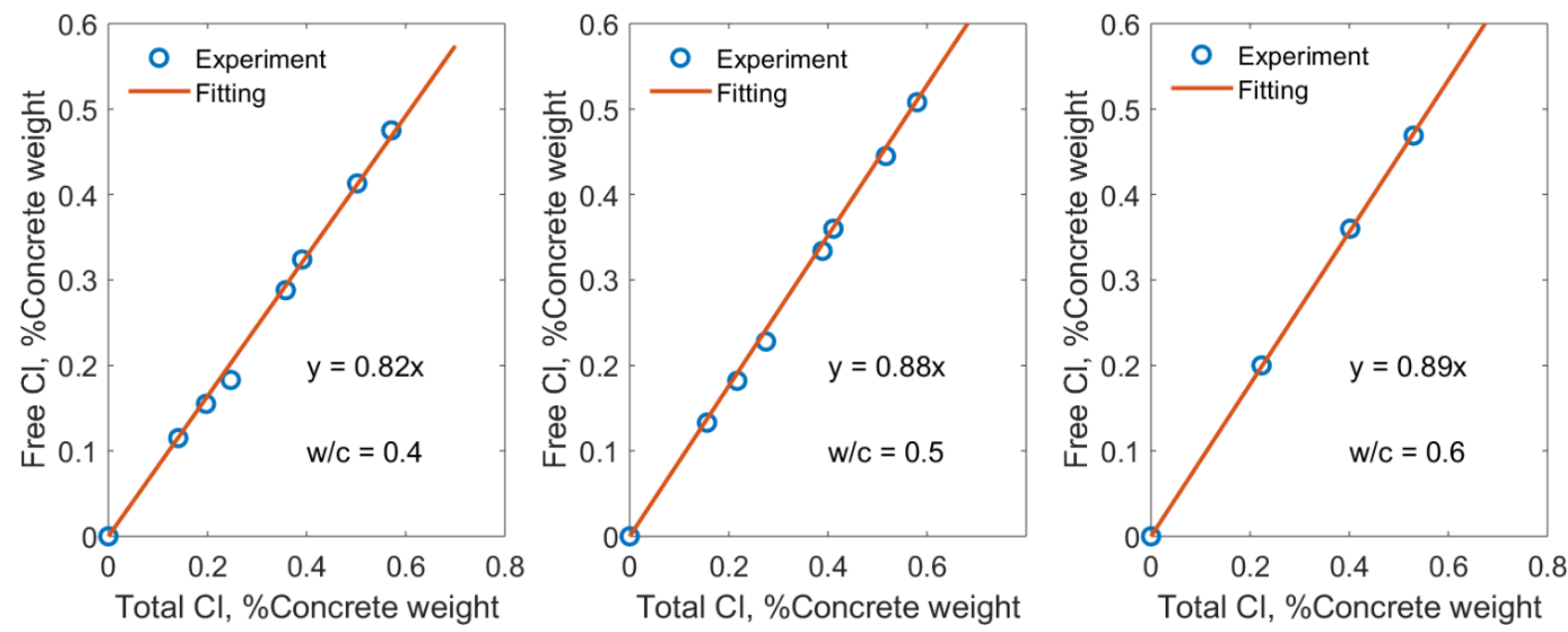

141

142

143

144

145

146

147

148

149

150

151

152

153

154

155

156

157

158

159

160

$(154$

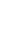

Figure 3. The relationship between the free and total chloride content

\section{Vapour-Water Sorption Characterisation}

The vapour-water sorption isotherm (VWSI) is an important property of concrete which plays an essential role in the modelling and analysis of moisture transport in concrete [30], and in the information for pore size distribution [31-33]. Although salty ions in concrete have a proven influence on the VWSI of concrete, so far, specific research on the topic is still limited. Particularly, more profound work is still necessary in order to provide a reliable mathematical characterisation model to quantify the influence. A previous research has suggested that the water retention in unsaturated porous materials is driven by the vapour absorption of the pore surface and the water condensation in pore voids due to the physical-chemical interfacial forces at pore surfaces [34]. This fundamental understanding generates an analytic mathematical model for the VWSI of hardened concrete as shown below $[35,36]$ :

where $S_{c}$ is capillary suction of unsaturated concrete, $S_{w}$ is the pore water saturation in concrete, and $\alpha, \beta$ and $\lambda$ are three interfacial physical-chemical parameters decided by material nature, pore structure and the interfacial forces at pore surfaces [34-36]. For engineering convenience purposes, it is suggested that Eq. (1) be simplified into the form of Eq. (2) below, where $f_{0}=\lambda\left(\frac{1}{\beta}-\frac{1}{\alpha}\right)$ and 
Journal: Construction and Building Materials - JCBM_119074 (April 2020)

161 the single parameter $P_{0}$ is adopted to reflect the coupled effect of the $\frac{\lambda}{\alpha}$, a term related to the water 162 phase in filled pores and $\frac{\lambda}{\beta}$, a term related to the vapour phase in co-existing empty pores [35].

163

164

$$
S_{c}=f_{0}+P_{0}\left[e^{\alpha S_{w}}-e^{\beta\left(1-S_{w}\right)}\right]
$$

The simplified form of Eq. (2) has been not only successfully used for concrete VWSI modelling 167 [35] but has also been applied to other physical properties of other porous materials, such as soils [36-38]. This paper revises Eq. (2) using an exponential weighing function to reflect the osmotic effect of chloride on the water suction capacity of concrete. The proposed model takes the form of Eq. (3) below:

171

$$
S_{c}=e^{\gamma C l}\left[f_{0}+P_{0}\left(e^{\alpha S_{w}}-e^{\beta\left(1-S_{w}\right)}\right)\right]
$$

where $\mathrm{Cl}$ is the chloride content, and $\gamma$ is a constant parameter determined by fitting Eq. (3) to experimental measurement.

To use Eqs. (2) and (3) to characterise the experimental data in Fig. 1, we need to work out the concrete suction at different water contents. Under equilibrium with environmental moisture, concrete suction can be evaluated in terms of the moisture relative humidity [39], i.e.:

$$
S_{c}=\left|R T \ln (R H) / V_{w}\right|
$$

where $R$ is gas constant, $T$ is the temperature in Kelvin, $R H$ is relative humidity and $V_{w}$ is the molar volume of water.

Fig. 4 is a replot of the data in Fig. 1(b) by replacing the RH using $S_{c}$ in terms of Eq. (4), assuming a temperature of $21^{\circ} \mathrm{C}$, and $V_{w}=18.03 \times 10^{-6} \mathrm{~m}^{3} / \mathrm{mole}$. The modelling curves are the results of using Eq. (2) to fit the experimental data. The fitting was conducted using MATLAB. The modelling results show that Eq. (2) well represents the vapour absorption and the water retention 
Journal: Construction and Building Materials - JCBM_119074 (April 2020)

190 characteristics, i.e. the VWSI of concrete under certain chloride salt contents and porosity 191 conditions. The fitting curves in the cases of $w / c=0.5$ and 0.6 do not reach the experimental data 192 of the full saturation condition $S_{w}=1$. This may be explained as being due to microcracks in the 193 concrete samples, where pore water subjects a very small suction [33]. The fitting tool is beyond 194 its lowest accuracy at such low suction values. A further research is ongoing to address this issue. 195
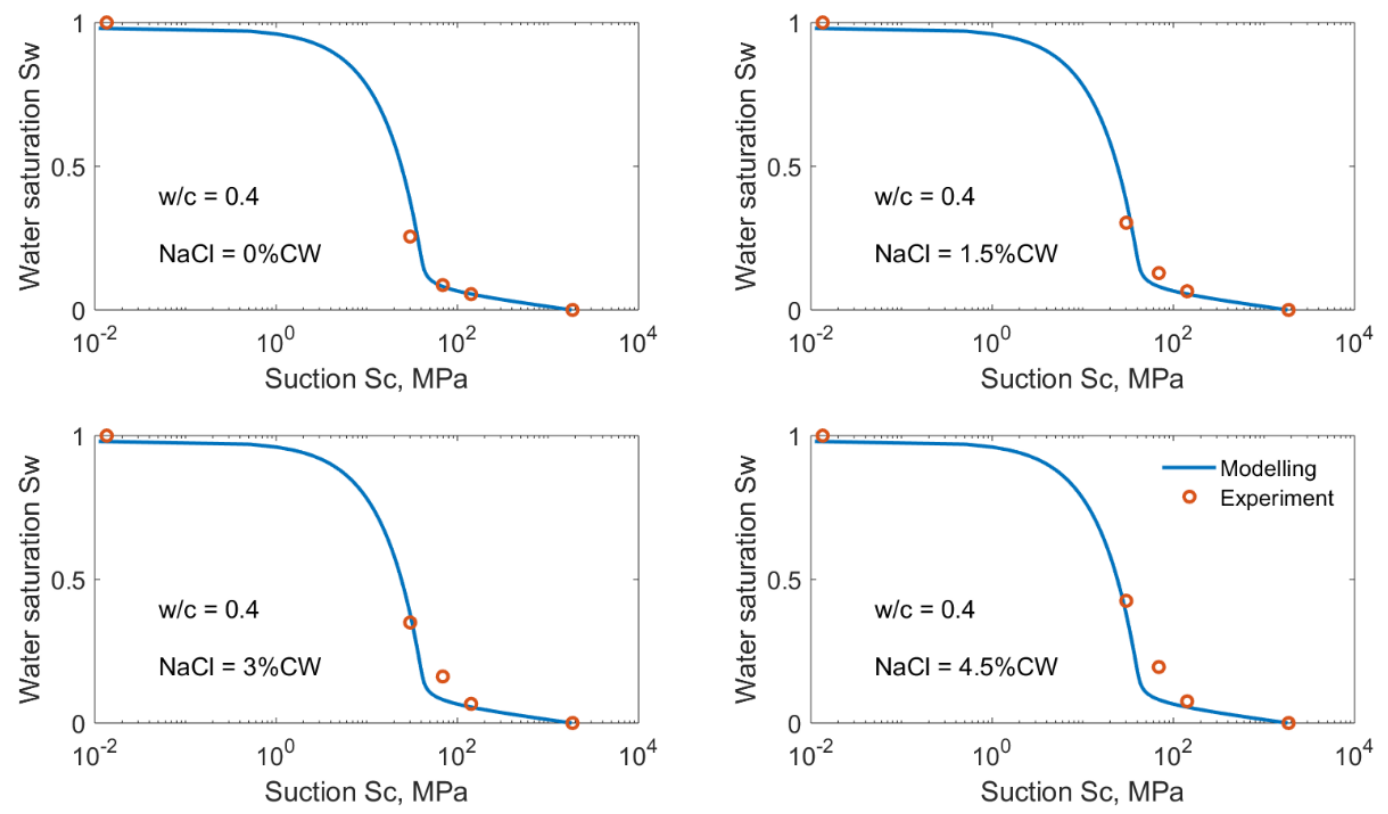

196

(a) $w / c=0.4$ 
Journal: Construction and Building Materials - JCBM_119074 (April 2020)
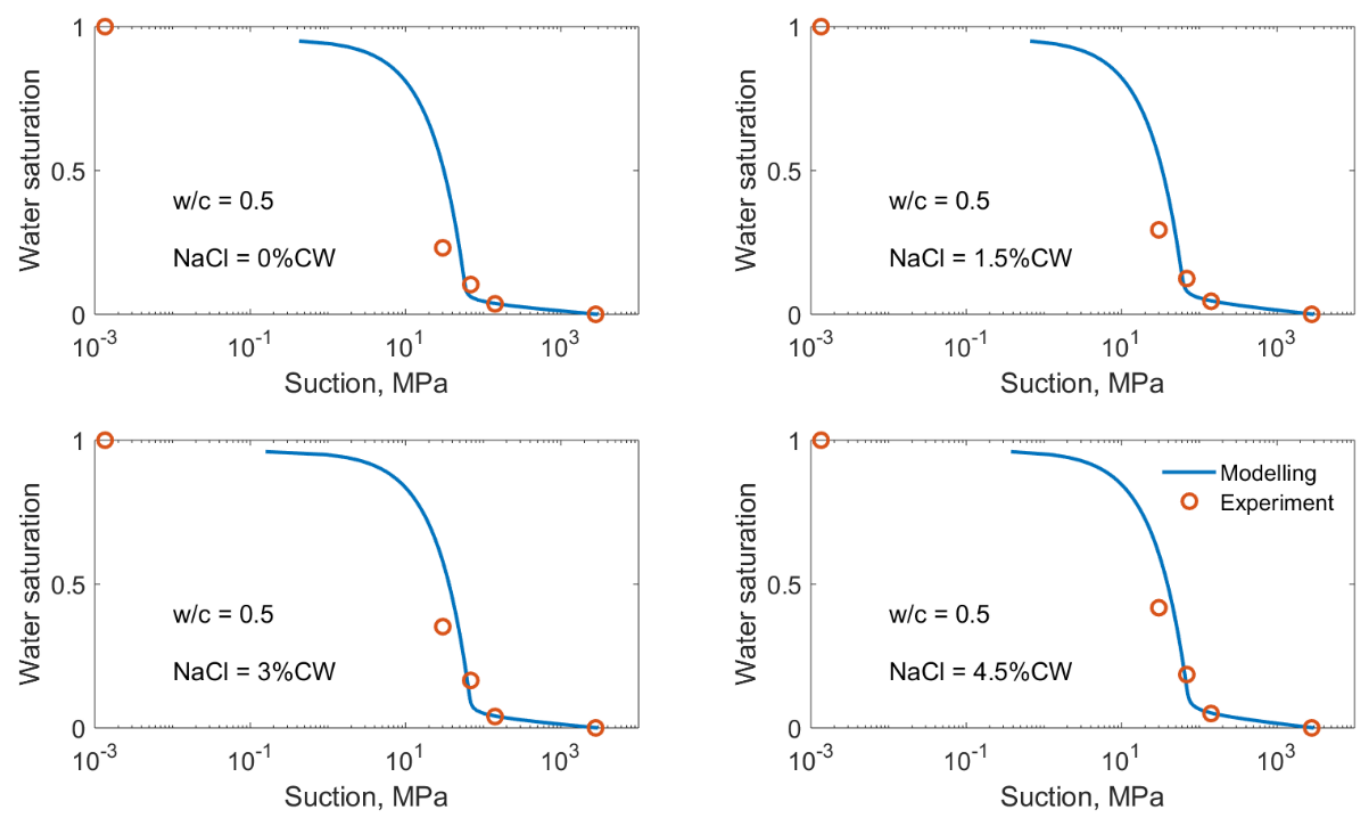

(b) $\mathrm{w} / \mathrm{c}=0.5$
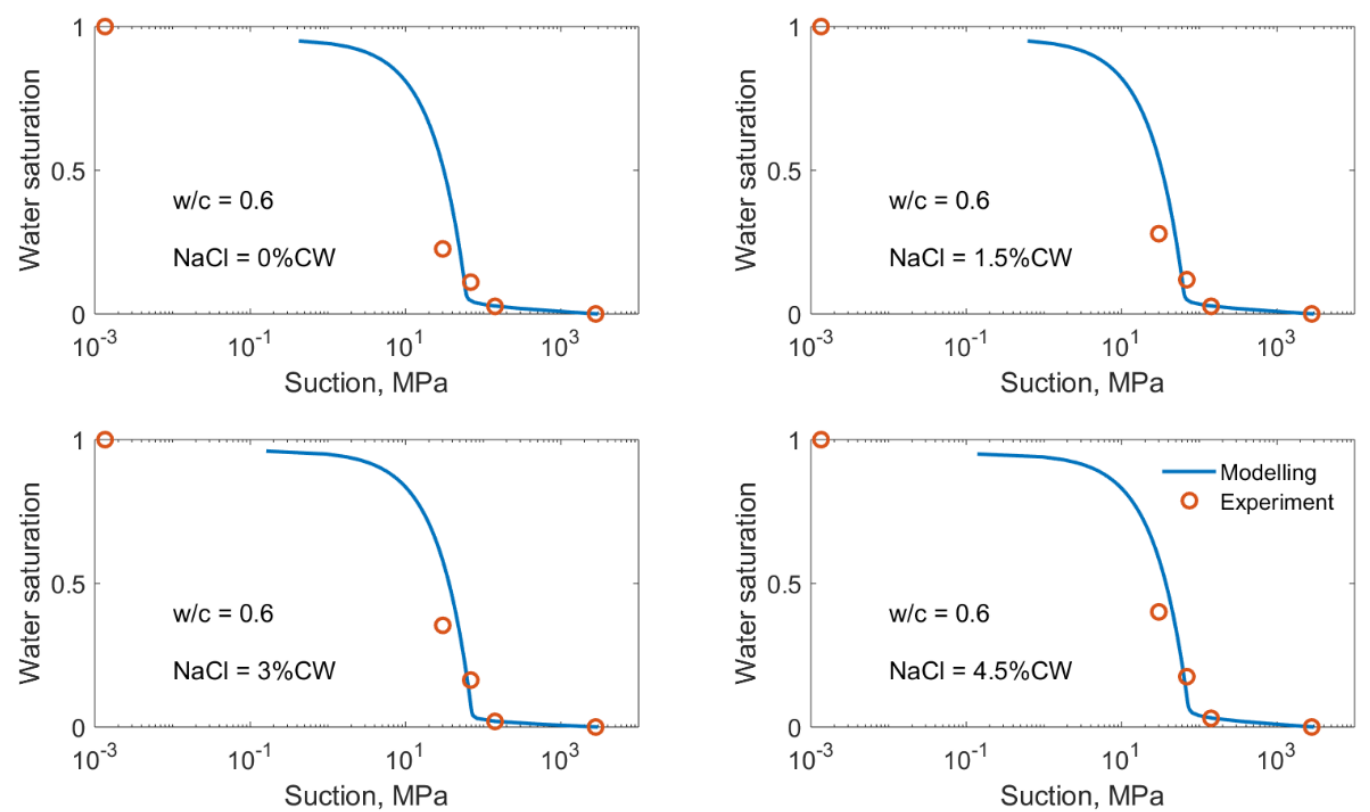

(c) $\mathrm{w} / \mathrm{c}=0.6$

Figure 4. The modelled VWSI curves at certain chloride contents

204 Fig. 5 shows the results using Eq. (3) to fit all the experimental data in each specific w/c cases in Fig. 4. All the data in each w/c case stands for a surface in the space of suction $\left(\mathrm{S}_{\mathrm{c}}\right)$, pore water 
Journal: Construction and Building Materials - JCBM_119074 (April 2020) saturation $\left(\mathrm{S}_{\mathrm{w}}\right)$ and chloride content, where $\mathrm{Cl} / \mathrm{CW}$ is the chloride content $(\mathrm{Cl})$ in terms of the dry concrete weight $(\mathrm{CW})$ under a certain $\mathrm{NaCl}$ addition. The obtained characterisation surface obtained using Eq. (3) to fit these experimental data well represents the VWIS in the whole range of both the water and chloride contents except at a fully dry state. The fully dry state was excluded when undertaking the surface fitting because it is hard to identify the starting point at a fully dry state. Table 2 lists the corresponsive fitting parameter data obtained. The RMSE (root-mean-square error) and the R-squared are defined as:

4

15

$$
R M S E=\sqrt{\frac{\sum_{i=1}^{n}\left(y_{i}-\mathrm{f}_{i}\right)^{2}}{n}}
$$$$
R-\text { squared }=\sqrt{1-\frac{\sum_{i=1}^{n}\left(y_{i}-\mathrm{f}_{i}\right)^{2}}{\sum_{i=1}^{n}\left(y_{i}-\bar{y}_{l}\right)^{2}}}
$$

where $\bar{y}_{l}$ is the average of all the experimental data $y_{i}, n$ is the total number of the experimental data, $f_{i}$ is the modelling value from the data fitting. The lower the RMSE value the better the modelling. Meanwhile, a value of R-squared closer to 1 indicates that the model has almost all the variability of the response data around its mean.

Table 2. The obtained fitting parameters in Eq. (3) for the results in Fig. 4

\begin{tabular}{|c|c|c|c|c|c|c|c|}
\hline $\mathrm{w} / \mathrm{c}$ & $\gamma$ & $\mathrm{f}_{0}$ & $\mathrm{P}_{0}$ & $\alpha$ & $\beta$ & RMSE & R-square \\
\hline 0.4 & 0.9104 & 390.9 & 391.9 & -25.76 & -1.23 & 8.789 & 0.9811 \\
\hline 0.5 & 0.3661 & 163.4 & 163.5 & -11.96 & -0.2762 & 7.777 & 0.9871 \\
\hline 0.6 & 0.1867 & 137.9 & 137.8 & -9.438 & -0.2945 & 8.022 & 0.9862 \\
\hline
\end{tabular}


Journal: Construction and Building Materials - JCBM_119074 (April 2020)
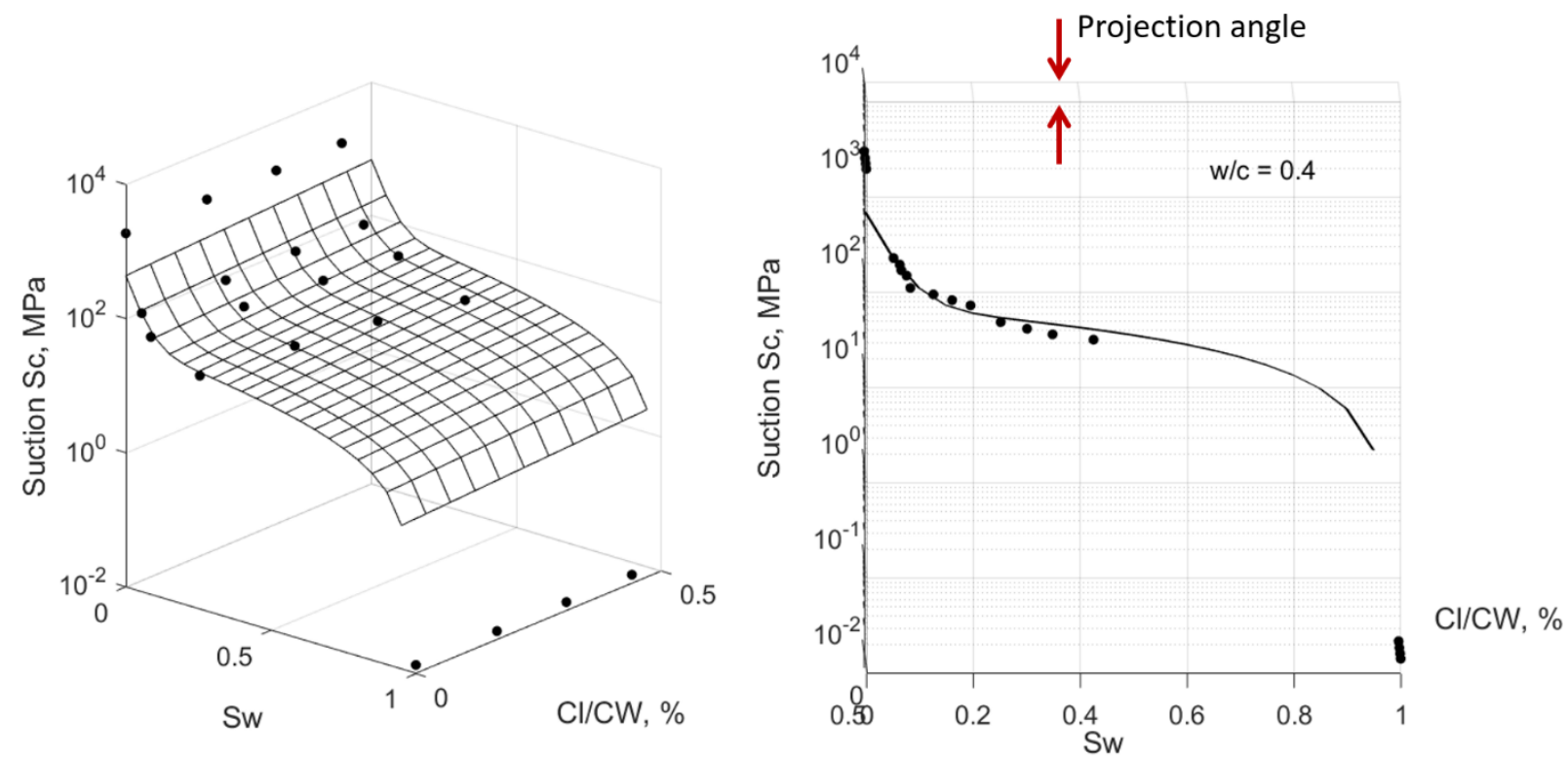

224

225

Modelled VWSI surface

The projection on $\mathrm{S}_{\mathrm{c}}-\mathrm{S}_{\mathrm{w}}$ plane

(a) $w / c=0.4$

227

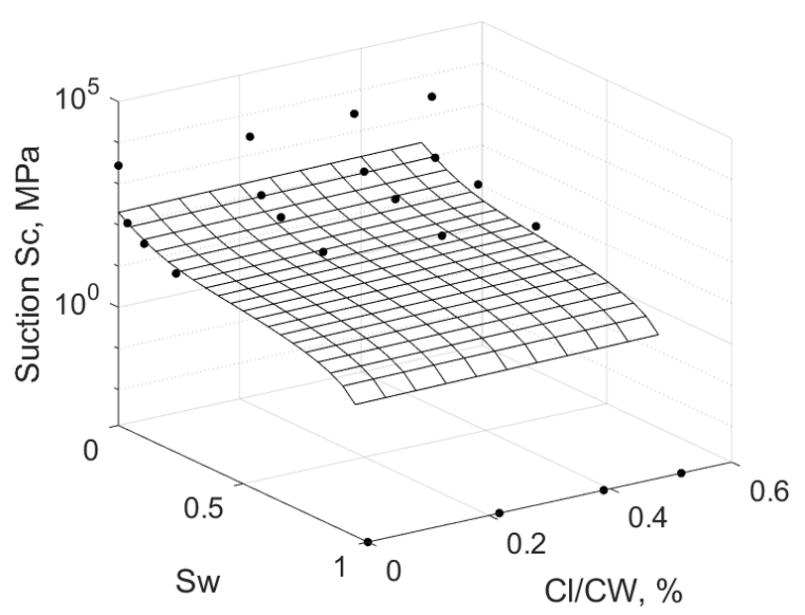

228

229

230

231

232

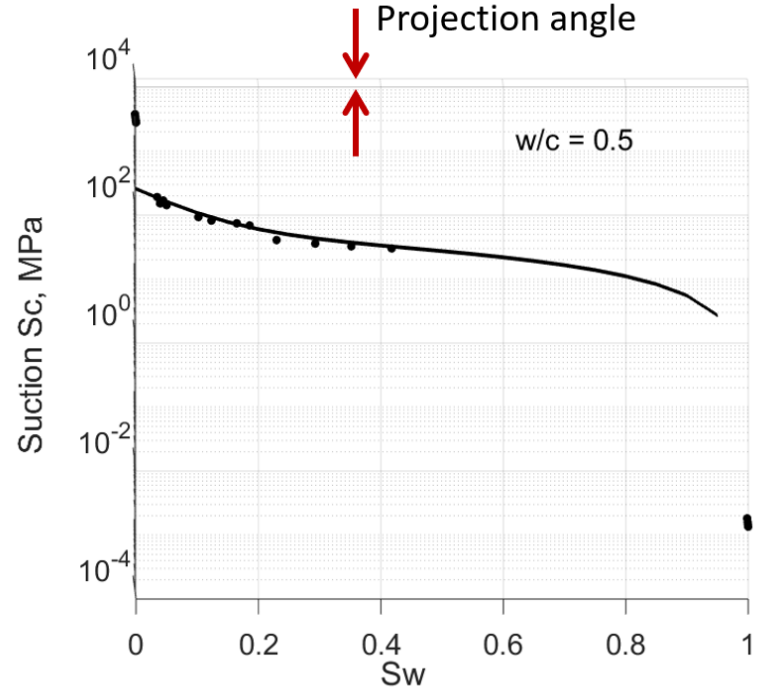

The projection on $S_{c}-S_{w}$ plane 


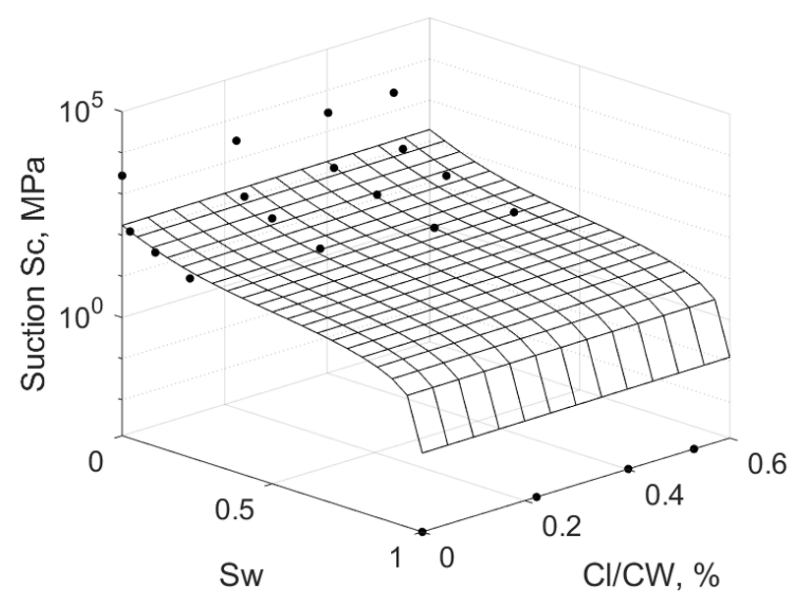

Modelled VWSI surface

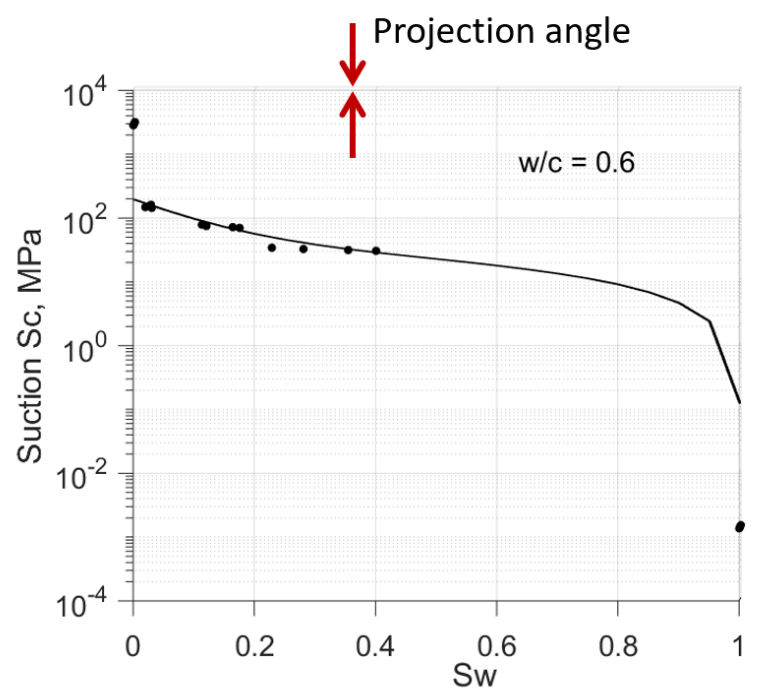

The projection on $\mathrm{S}_{\mathrm{c}}-\mathrm{S}_{\mathrm{w}}$ plane
234

235

236

237

238

239

240

241

242

243

244

245

246

247

248

249

250

$$
\begin{aligned}
& \tau \frac{\partial}{\partial t}\left(C_{i}+S_{i}\right)=z_{i} \nabla\left[D_{i}\left(\frac{F}{R T} \nabla \phi\right) C_{i}\right]+\nabla\left(D_{i} \nabla\left(C_{i}\right)\right)-\tau \nabla\left(C_{i} v\right) \\
& \frac{F}{R T} \nabla \phi=-\frac{\frac{\tau I}{F \varepsilon}+\sum_{i}^{n} z_{i} D_{i} \nabla C_{i}}{\sum_{i}^{n} z_{i}^{2} D_{i} C_{i}}
\end{aligned}
$$

Figure 5. VWSI in 3D $\mathrm{S}_{\mathrm{c}}-\mathrm{S}_{\mathrm{w}}-\mathrm{Cl} / \mathrm{CW}$ space salt content on VWSI becomes less when concrete porosity increases.

\section{Modelling Chloride Ingress in Tidal Zones}

\subsection{Modelling chloride transportation in unsaturated concrete} pore solution can be expressed as $[3,40]$ :

The projection angle, which reflects the effect of $\mathrm{Cl}$, is to make the projection of the VWSI surface on the $\mathrm{S}_{\mathrm{c}}-\mathrm{S}_{\mathrm{w}}$ plane (or in the axis of $\mathrm{Cl} / \mathrm{CW}$ ) close to a single curve. It can be seen that the higher the w/c the lower the projection angle, thus demonstrating the fact that the osmotic effect of the

This paper incorporates Eq. (3) into a process model for chloride ingress in concrete. In terms of the ionic concentration in pore water, the governing equations for the ions' transport in concrete

251 
Journal: Construction and Building Materials - JCBM_119074 (April 2020)

252 The left-hand-side of Eq. (7) stands for the rate of the local chloride concentration change, where

$253 \tau$ is the tortuosity of the pore network, $C_{i}$ is the concentration of ionic species $i$, in concrete pore

254 water, $t$ is time, $S_{i}$ is the concentration of ionic species in concrete solid phase in terms of the pore 255 water volume. On the right-hand-side of Eq. (7), the first term stands for the ions' migration due 256 to the local electrical interaction between the ions (Eq. (8)), where $z_{i}$ is the ions' charge number, $257 F$ is the Faraday's constant, $R$ is gas constant, $T$ is kelvin temperature, $D_{i}$ is the diffusion 258 coefficient of ions in pore water, $\phi$ is the local electrostatic potential in pore water, $n$ is the total 259 number of ionic species in concrete pore water, $I$ is the electrical current density applied externally 260 on the concrete, such as in case of cathodic protection. For the following case study in the next 261 section 4.2, there is no external applied electrical current, i.e. $I=0$. The second term stands for the 262 ions' diffusion under concentration gradient. The third term stands for the ions' convection with 263 the flow of pore water, where $v$ is the superficial velocity of bulk pore water in concrete.

265 For unsaturated concrete, to close Eqs. (7) and (8), the pore water velocity, $v$, is required. Water 266 flow in porous media is a topic of hydrology. The water flow in pores is driven by two forces, i.e., 267 the gravity due to elevation and the capillary suction at an unsaturated state. The flow driven by 268 the latter is called wick action. The first one is proportional to the gradient of the water head, while 269 the second one is fundamentally linked to the pore water saturation degree and the VWSI. An 270 unsaturated flow theory [41] was developed by extending the original Darcy's law for a saturated 271 state to an unsaturated state. The modified Darcy equation takes the form below:

272

273

274

275

$$
v=-K_{w} \nabla(p+\rho g z)
$$
suction in negative value, and $\rho g z$ is the gravity potential given water density $\rho$, gravity $g$ and elevation $z$. Both $K_{w}$ and $p$ depend on the water saturation degree. If we neglects the elevation effect, by substituting a negative value of $S_{c}$ of Eq. (3) into Eq (9) for $p$, we obtain:

$$
v=-K_{w} \nabla\left(-S_{c}\right)=-K_{w} \frac{\partial\left(-S_{c}\right)}{\partial S_{w}} \nabla S_{w}
$$


Journal: Construction and Building Materials - JCBM_119074 (April 2020)

282 Rewriting Eq. (10) into the form below:

283

284

285

286

287 288

289

290

291

292

293

294

295

296

297

298

299

300

301

302

303

304

305

306

307

308

309

310

311

$$
v=-D_{w} \nabla S_{w}
$$

where $D_{w}=K_{w} \frac{\partial\left(-S_{c}\right)}{\partial S_{w}}=K_{w} e^{a C l}\left[-P_{0}\left(\alpha e^{\alpha S_{w}}+\beta e^{\beta\left(1-S_{w}\right)}\right)\right]$ is called hydraulic diffusivity. In addition, water flow in concrete also meets the mass conservation, i.e.:

$$
\frac{d S_{w}}{d t}=-\nabla v
$$

Substituting Eq. (11) into Eq. (12), we at last have:

$$
\frac{d S_{w}}{d t}=\nabla\left(D_{w} \nabla S_{w}\right)
$$

Now Eqs. (7), (8), (11) and (13) are closed. They deterministically define ions' transport in unsaturated concrete. In the next section, we applied the closed equation system to simulate a concrete column exposed in a tidal zone.

\subsection{A simulation case study}

A $2 \mathrm{~m}$ high concrete $(\mathrm{w} / \mathrm{c}=0.4)$ column with a diameter of $1 \mathrm{~m}$ stands in salty water of $1 \mathrm{~m}$ depth. It is assumed that 0.5 meter above the bulk water surface level is subject to tidal splash. Assuming that the average environmental humidity is $\mathrm{RH}=75 \%$, and referring to the data in Fig. 2, the initial and boundary conditions are defined as:

1. $\mathrm{S}_{\mathrm{w}}=1, \mathrm{~h}<=1 \mathrm{~m}$ (h is the vertical height along the column),

2. $\mathrm{S}_{\mathrm{w}}=0.2, \mathrm{~h}>1.5 \mathrm{~m}$,

3. At the concrete surface in a tidal zone $(\mathrm{h}=1 \sim 1.5 \mathrm{~m}), \mathrm{S}_{\mathrm{w}}=\max (\sin (\pi / 12 \times \mathrm{t}), 0.2)(\mathrm{t}$ is time in hours), as showed in Fig. 6.

A hydraulic conductivity model for unsaturated flow in hydrology is adopted [39], which is:

$$
K_{w}=K_{s} S_{w}^{n}
$$


Journal: Construction and Building Materials - JCBM_119074 (April 2020)

312 where $K_{s}$ is saturated hydraulic conductivity.

314

315

316

317 Salty water is assumed to be a solution of $479 \mathrm{~mole} / \mathrm{m}^{3} \mathrm{NaCl}$. Four main types of ions in concrete pore water are taken into account by hypothesis; they are chloride $\left(\mathrm{Cl}^{-}\right)$, sodium $\left(\mathrm{Na}^{+}\right)$, potassium $\left(\mathrm{K}^{+}\right)$and hydroxide $(\mathrm{OH}-)$. The other parameters and initial data adopted are listed in Table 3 (the data in Table 3 are based purely on assumption and refer to some information presented in previous publications $[3,40]$. However, there is some most recent work $[42,43]$ that can be referred to, which will help the selected data to be closer to reality).

Table 3. Parameters and data used in simulation

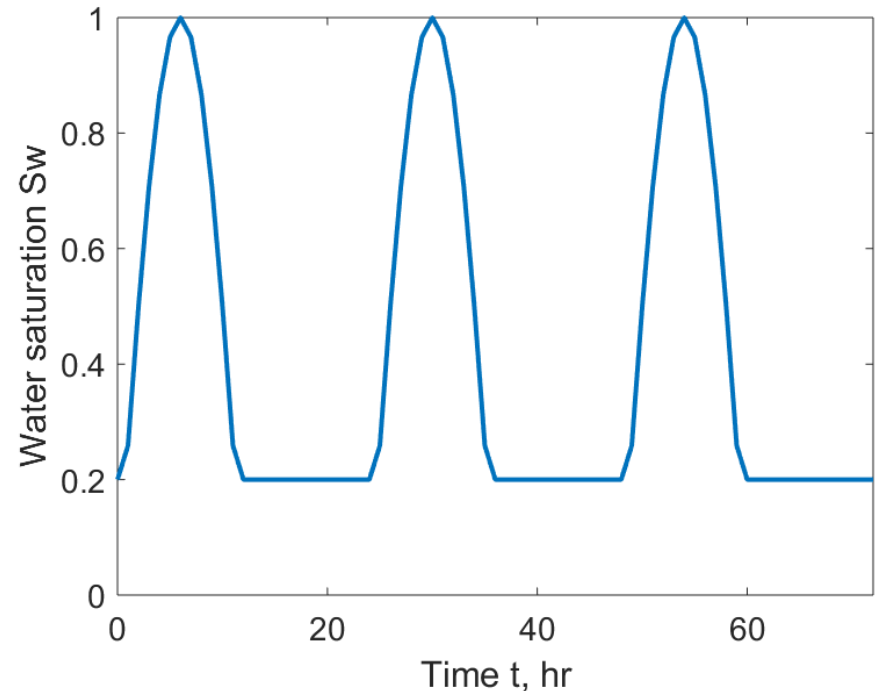

Figure 6. Boundary condition in the tidal zone

\begin{tabular}{|c|c|c|c|c|}
\hline \multicolumn{5}{|c|}{ Eqs. (7) \& (8) } \\
\hline $\begin{array}{c}\text { Diffusion coefficient, } D_{i} \\
\mathrm{~m}^{2} / \mathrm{s}\end{array}$ & $2.03 \times 10^{-9}$ & $1.334 \times 10^{-9}$ & $1.957 \times 10^{-9}$ & $5.27 \times 10^{-9}$ \\
\hline $\begin{array}{c}\text { Initial concentration in concrete } \\
\text { mole/m }\end{array}$ & 5 & 5 & 490 & $\begin{array}{c}{\left[\mathrm{OH}^{-}\right]+\left[\mathrm{Cl}^{-}\right]=} \\
{\left[\mathrm{Na}^{+}\right]+\left[\mathrm{K}^{+}\right]}\end{array}$ \\
\hline Tortuosity, $\tau$ & & & & \\
\hline Porosity, $\varepsilon$ & & \multicolumn{3}{|c|}{0.167} \\
\hline
\end{tabular}


Journal: Construction and Building Materials - JCBM_119074 (April 2020)

\begin{tabular}{|c|c|}
\hline $\begin{array}{c}\text { Bound Chloride } \\
\text { Mole/m }\end{array}$ & $\begin{array}{c}S_{c l}=0.223 C_{C l} \\
\text { In terms of the linear relationship in Fig. 2 }\end{array}$ \\
\hline $\begin{array}{c}\text { Eq. (14) } \\
(\mathrm{m} / \mathrm{s})\end{array}$ & $5 \times 10^{-16}$ \\
\hline$n$ & 2 \\
\hline
\end{tabular}

325

326

327

328

329

330

331

332

333

334

335

336

337

338

\subsection{Modelling results}

Fig. 7 shows the water saturation degree and the chloride profile in the symmetric half of the column at the initial stage and after exposure to tidal splash for one year. It can be seen that cyclic tidal splash accelerates the chloride ingress into the concrete at the region of the bulk water surface $(y=1 \mathrm{~m})$. Fig. 8 compares the chloride profiles in the column at the bottom underwater $(y=0)$ and at the level of the bulk water surface $(y=1 \mathrm{~m})$ after 1 year. It can be seen that both splash and osmotic effects have enhanced the chloride ingress in the tidal region, but water splash is much more significant than the osmotic action in terms of influence.

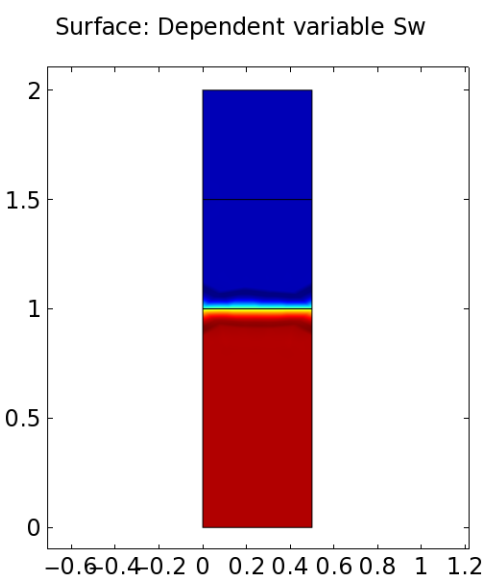

(a) Water saturation

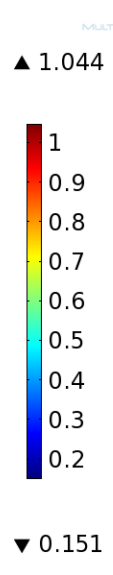

(a). Initial condition, $\mathrm{t}=0 \mathrm{hr}$ 
Journal: Construction and Building Materials - JCBM_119074 (April 2020)

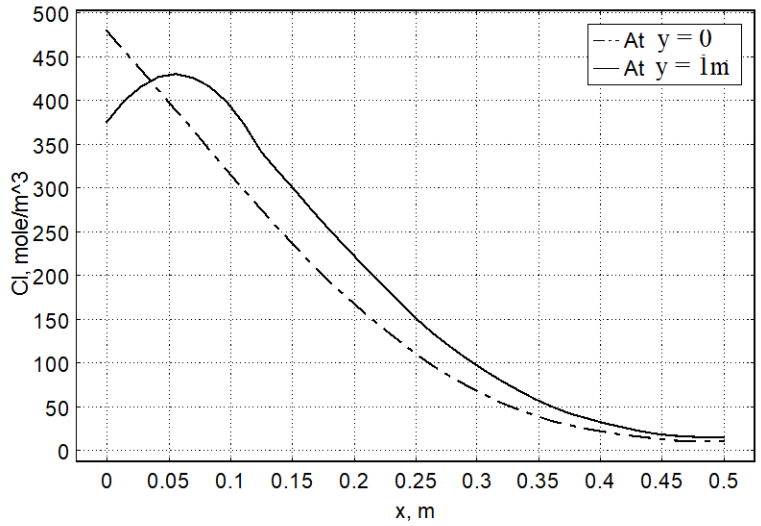

(a) With osmotic effect

(a) Water saturation
Surface: Dependent variable $\mathrm{C} \mathrm{Cl}$

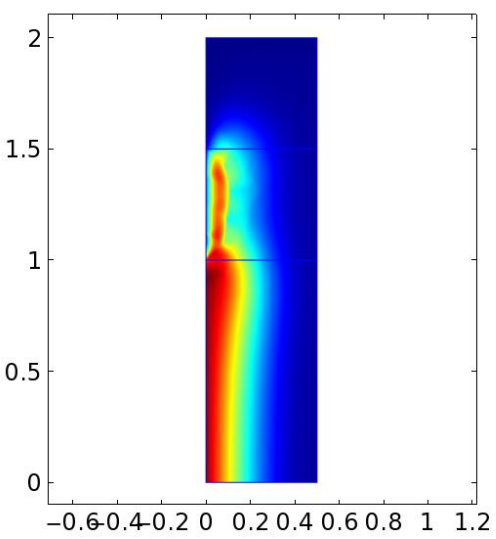

488.2

450

400

350

300

200

150

50

$\boldsymbol{\nabla}-4.614$

(b) Chloride concentration, mole $/ \mathrm{m}^{3}$

(b). After 1 year, $\mathrm{t}=8736 \mathrm{hr}$

Figure 7. Water saturation and the chloride profile in the concrete column

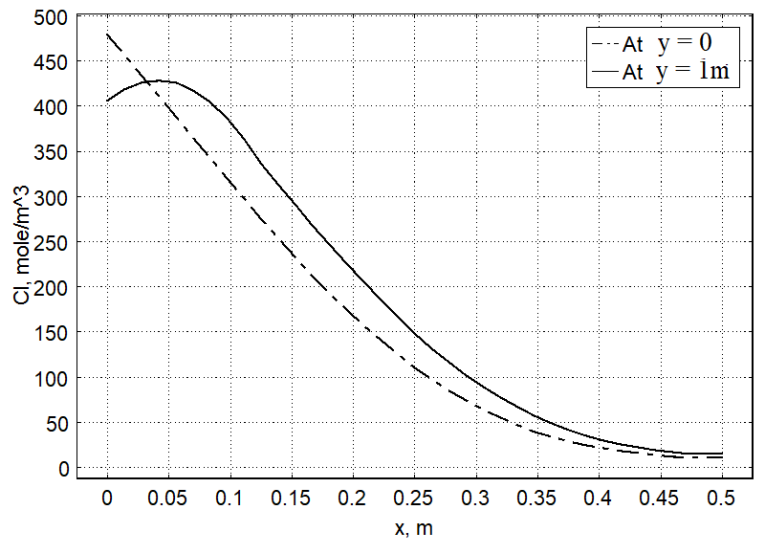

(b) Without osmotic effect ( $\gamma=0$ in Eq. (3)) 
Journal: Construction and Building Materials - JCBM_119074 (April 2020)

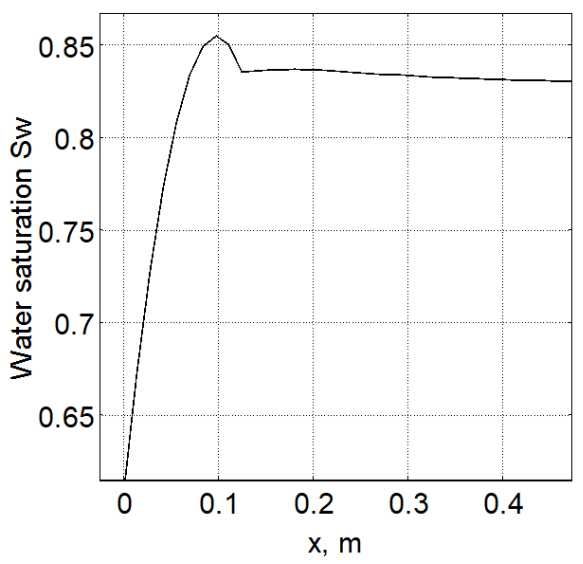

(a) With osmotic effect

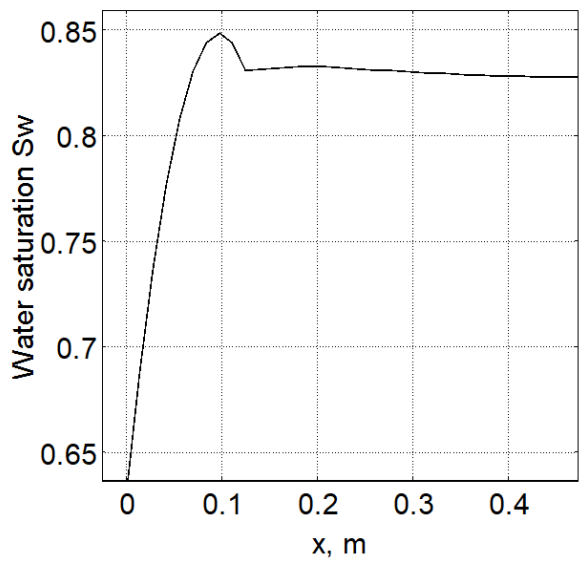

(b) Without osmotic effect ( $\gamma=0$ in Eq. (3)) Figure 9. The water saturation degree in concrete at the height $y=1 \mathrm{~m}$

This paper presents an experimental study of the chloride salt effect on the vapour-water sorption isotherm of concrete. An effective characteristic model has been proposed and validated using experimental data. The model has been successfully implemented to simulate chloride ingress in concrete structures in tidal zones. The following conclusions can be drawn: saturation degree when exposed to the same environmental humidity due to osmotic action.

2. The osmotic effect on the vapour-water sorption isotherm can be effectively characterised using a proposed mathematical model.

3. Chloride ingress in concrete is significantly increased in the underwater region in a tidal zone.

4. Osmotic action has an influence on chloride diffusion in concrete but has a much lesser influence on water ingress.

\section{Acknowledgements}

1. The experiment work was funded by the Iraqi Ministry of Higher Education and Scientific Research Scholarship Programme.

2. A sincere thanks to Ms Hanneke van Dijk at the University of Salford for her diligent proofreading of this paper. 
Journal: Construction and Building Materials - JCBM_119074 (April 2020)

378

379

380

381

382

383

384

385

386

387

388

389

390

391

392

393

394

395

396

397

398

399

400

401

402

403

404

405

406

407

408

\section{References}

[1] G. Sergi, S. Yu, C. Page, Diffusion of chloride and hydroxyl ions in cementitious materials exposed to a saline, Magazine of Concrete Research 44(158) (1992) 63-69.

[2] K. Maekawa, T. Ishida, Modeling of structural performances under coupled environmental and weather actions, Materials and Structures 35(10) (2002) 591-602.

[3] Y. Wang, L.-Y. Li, C. Page, Modelling of chloride ingress into concrete from a saline environment, Building and Environment 40(12) (2005) 1573-1582.

[4] G. Lin, Y. Liu, Z. Xiang, Numerical modeling for predicting service life of reinforced concrete structures exposed to chloride environments, Cement and Concrete Composites 32(8) (2010) 571579.

[5] P. Zhang, D. Hou, Q. Liu, Z. Liu, J. Yu, Water and chloride ions migration in porous cementitious materials: An experimental and molecular dynamics investigation, Cement and Concrete Research 102 (2017) 161-174.

[6] A. Ababneh, F. Benboudjema, Y. Xi, Chloride penetration in nonsaturated concrete, Journal of Materials in Civil Engineering 15(2) (2003) 183-191.

[7] D. Conciatori, H. Sadouki, E. Brühwiler, Capillary suction and diffusion model for chloride ingress into concrete, Cement and Concrete Research 38(12) (2008) 1401-1408.

[8] S. Meijers, J. Bijen, R. De Borst, A. Fraaij, Computational results of a model for chloride ingress in concrete including convection, drying-wetting cycles and carbonation, Materials and Structures 38(2) (2005) 145-154.

[9] E. Samson, J. Marchand, K.A. Snyder, J. Beaudoin, Modeling ion and fluid transport in unsaturated cement systems in isothermal conditions, Cement and Concrete Research 35(1) (2005) 141-153.

[10] K. Hong, R. Hooton, Effects of cyclic chloride exposure on penetration of concrete cover, Cement and Concrete Research 29(9) (1999) 1379-1386.

[11] Z. Yu, Y. Chen, P. Liu, W. Wang, Accelerated simulation of chloride ingress into concrete under drying-wetting alternation condition chloride environment, Construction and Building Materials 93 (2015) 205-213.

[12] J. Wu, H. Li, Z. Wang, J. Liu, Transport model of chloride ions in concrete under loads and drying-wetting cycles, Construction and Building Materials 112 (2016) 733-738. 
Journal: Construction and Building Materials - JCBM_119074 (April 2020)

[13] Y. Zhang and W.-L. Jin, Distribution of Chloride Accumulation in Marine Tidal Zone along Altitude, ACI Materials Journal (2011) 1-9.

[14] R.A. de Medeiros-Junior, M.G. de Lima, P.C. de Brito, M.H.F. de Medeiros, Chloride penetration into concrete in an offshore platform-analysis of exposure conditions, Ocean Engineering 103 (2015) 78-87.

[15] C. Sun, L. Yuan, X. Zhai, F. Qu, Y. Li, B. Hou, Numerical and experimental study of moisture and chloride transport in unsaturated concrete, Construction and Building Materials 189 (2018) 1067-1075.

[16] B.H. Oh, S.Y. Jang, Effects of material and environmental parameters on chloride penetration profiles in concrete structures, Cement and Concrete Research 37(1) (2007) 47-53. [17] A. Van der Zanden, A. Taher, T. Arends, Modelling of water and chloride transport in concrete during yearly wetting/drying cycles, Construction and Building Materials 81 (2015) 120-129.

[18] Q.-Z. Zhang, X.-L. Gu, Z.-L. Jiang, W.-P. Zhang, Similarities in Accelerated Chloride Ion Transport Tests for Concrete in Tidal Zones, ACI Materials Journal 115(4) (2018) 499-507. [19] A. Petcherdchoo, Closed-form solutions for modeling chloride transport in unsaturated concrete under wet-dry cycles of chloride attack, Construction and Building Materials 176 (2018) 638-651.

[20] P. Nguyen, O. Amiri, Study of electrical double layer effect on chloride transport in unsaturated concrete, Construction and Building Materials 50 (2014) 492-498. [21] J. Geng, L.-Y. Li, Y. Wang, Modelling of chloride penetration in unsaturated concrete, Advances in Cement Research 28(1) (2015) 51-61.

[22] D. Li, L.-Y. Li, X. Wang, F. Xing, A double-porosity model for water flow in unsaturated concrete, Applied Mathematical Modelling 53 (2018) 510-522.

[23] A.B. Fraj, S. Bonnet, A. Khelidj, New approach for coupled chloride/moisture transport in non-saturated concrete with and without slag, Construction and Building Materials 35 (2012) 761-771.

[24] C. Zhou, Prediction water permeability and relative gas permeability of unsaturated cementbased material from hydraulic diffusivity, Cement and Concrete Research 58 (2014) 143-151. [25] S. Saliba, P. Ruch, W. Volksen, T.P. Magbitang, G. Dubois, B. Michel, Microporous and Mesoporous Materials 226 (2016) 221-228. 
Journal: Construction and Building Materials - JCBM_119074 (April 2020)

440 [26] Q. Zeng, D.D. Zhang, H. Sun, K. Li, Characterizing pore structure of cement blend pastes

441 using water vapour sorption analysis, Materials Characterisation 95 (2014) 72-84.

442 [27] ASTM C1152/C1152M, Standard test method for acid-soluble chloride in mortar and 443 concrete, in, ASTM International, West Conshohocken, PA, USA, 2012.

444 [28] ASTM C1218/C1218M, Standard test method for water-soluble chloride in mortar and concrete, in, ASTM International, West Conshohocken, PA, USA, 2015.

446 [29] H.M. Oleiwi, Y. Wang, M. Curioni, X-Y Chen, G-W Yao, Augusthus-Nelson L., Ragazzon-

447 Smith A.H., Shabalin I., An experimental study of cathodic protection for chloride contaminated 448 reinforced concrete, Materials and Structures 51 (2018) 148.

449 [30] V. Baroghel-Bouny, M. Mainguy, T. Lassabatere, O. Coussy, Characterization and 450 identification of equilibrium and transfer moisture properties for ordinary and high-performance 451 cementitious materials, Cement Concrete Research 29 (1999) 1225-38.

452 [31] C.G. Shull, The determination of pore size distribution from gas adsorption data, Journal of 453 the American Chemical Society, 70 (1948) 1405-10.

454 [32] V. Baroghel-Bouny, Water vapour sorption experiments on hardened cementitious materials: 455 Part I: essential tool for analysis of hygral behaviour and its relation to pore structure, Cement 456 Concrete Research 37 (2007) 414-37.

457 [33] Z. Wu, H.S. Wong, C. Chen, N.R. Buenfeld, Anomalous water absorption in cement-based 458 materials caused by drying shrinkage induced microcracks, Cement and Concrete Research; 115 459 (2019) 90-104.

460 [34] Y. Wang, S.M. Grove, M.G. Anderson, A physical-chemical model for the static water 461 retention characteristic of unsaturated porous media. Advances in Water Resources, 31 (2008) $462723-735$.

463 [35] Y. Wang, X. Wang, M. Scholz, D. Ross, A physico-chemical model for the water vapour 464 sorption isotherm of hardened cementitious materials, Construction and Building Materials 35 465 (2012) 941-946.

466 [36] Y. Wang, Phase deterministic modelling of water retention in unsaturated porous media and 467 its potential in dynamic unsaturated flow application, Journal of Porous Media 13 (2010) 261468270. 
Journal: Construction and Building Materials - JCBM_119074 (April 2020)

469 [37] H. Jin, Y. Wang, Q. Zheng, H. Liu, E. Chadwick, Experimental Study and Modelling of the

470 Thermal Conductivity of Sandy Soils of Different Porosities and Water Contents, Applied

471 Science 7 (2017) 119.

472 [38] N. Xiang, Y. Wang, H.M. Oleiwi, E. Chadwick, G-W. Yao, L. Augusthus-Nelson, X-Y.

473 Chen, I. Shabalin, Modelling the electrical resistivity of concrete with varied water and chloride

474 contents, Magazine of Concrete Research (2019).

475 [39] D. Hillel, Environmental Soil Physics, $1^{\text {st }}$ Edition, Adademic Press, 1998.

476 [40] Y. Wang, Chloride Transport in Concrete: Mathematical Description and Modelling. VDM

477 Verlag Dr. Müller 2011; Riga, Latvia.

478 [41] J.R. Philip, Theory of infiltration, Advance Hydroscience, 5 (1969) 215-296.

479 [42] M.H.N.Yio, H.S.Wong, N.R.Buenfeld, 3D pore structure and mass transport properties of 480 blended cementitious materials, Cement and Concrete Research 117 (2019) 23-37.

481 [43] M.H.N. Yio, M.J. Mac, H.S. Wong, N.R. Buenfeld, 3D imaging of cement-based materials at 482 submicron resolution by combining laser scanning confocal microscopy with serial sectioning, 483 Journal of Microscopy, 258 (2015)151-169.

484 